\title{
Microsurgical Breast Reconstruction in Thin Patients: The Impact of Low Body Mass Indices
}

\author{
Katie E. Weichman, MD ${ }^{1} \quad$ Neil Tanna, MD, MBA ${ }^{1} \quad$ P. Niclas Broer, MD ${ }^{1} \quad$ Stelios Wilson, MD ${ }^{1}$ \\ Hamdan Azhar, MS ${ }^{1} \quad$ Nolan S. Karp, MD ${ }^{1}$ Mihye Choi, MD ${ }^{1}$ Christina Y. Ahn, MD $\quad$ Jamie P. Levine, MD ${ }^{1}$ \\ Robert J. Allen Sr., MD ${ }^{1}$ \\ ${ }^{1}$ Institute of Reconstructive Plastic Surgery, New York University, \\ New York, New York \\ Address for correspondence Neil Tanna, MD, MBA, Department of \\ Plastic and Reconstructive Surgery, New York University, 550 First \\ J Reconstr Microsurg 2015;31:20-25. \\ Avenue, New York, NY 10016 (e-mail: ntanna@gmail.com).
}

\begin{abstract}
Keywords

- low BMI

- breast reconstruction

- thin

Background The purpose of this investigation was to examine patients with low body mass index (BMI) regarding the feasibility to perform autologous breast reconstruction in such patients, as well as to determine optimal donor sites and evaluate outcomes accordingly.

Patients and Methods All patients undergoing microsurgical breast reconstruction were divided into three cohorts based on BMI. Group 1 included patients with BMI greater than or equal to $22 \mathrm{~kg} / \mathrm{m}^{2}$ and was defined "low-normal BMI." Patients with BMI 22 to $25 \mathrm{~kg} / \mathrm{m}^{2}$ were placed in Group 2, labeled as "high-normal BMI." Group 3, defined as "overweight," included patients with BMl greater than $25 \mathrm{~kg} / \mathrm{m}^{2}$, but less than $30 \mathrm{~kg} / \mathrm{m}^{2}$. Patients were then analyzed based on demographics, breast cancer history, intraoperative details, complications, and revisionary surgeries. F-tests, chi-square goodness-of-fit tests, and Freeman-Halton extension of the Fisher exact tests were used for statistical analysis.

Results During the study period, a total of 259 reconstructions were performed. Group 1 included 30 patients ( $n=49$ flaps), Group 2 included 58 patients ( $n=98$ flaps), and Group 3 included 69 patients ( $n=112$ flaps). Patients undergoing nippleareolar sparing mastectomy were more likely to be in Groups $1(39 \%[n=19])$ and 2 $(37 \%[n=37])$ as compared with Group $3(14.2 \%[n=16])(p<0.001)$ as compared with the overweight cohort. Patients with increasing BMI were more likely to undergo abdominally based free flaps as compared with alternative donor sites (Group $1=2.26$, Group $2=7.9$, Group $3=27$ [ $p<0.001])$.

Conclusions Abdominally based free flaps are possible in the majority of patients, however alternative harvest sites have to be used more frequently in low BMI patients.
\end{abstract}

Patients undergoing autologous breast reconstruction have been shown to have higher overall rates of long-term satisfaction when compared with patients with implant-based reconstructions. ${ }^{1-5}$ While there is a national trend toward increasing rates of implant-based breast reconstructions, certain centers show microsurgical breast reconstruction is

received

January 25, 2014

accepted after revision

March 10, 2014

published online

June 9, 2014 being increasingly performed for both therapeutic and prophylactic indications. ${ }^{6-10}$ This rise in the use of autologous tissue for breast reconstruction is likely because of both an expanding spectrum of patients who are being offered free tissue transfer as well as an overall rising incidence breast reconstruction.
Copyright $\odot 2015$ by Thieme Medical Publishers, Inc., 333 Seventh Avenue, New York, NY 10001, USA. Tel: +1(212) 584-4662.
DOI http://dx.doi.org/ 10.1055/s-0034-1376398. ISSN 0743-684X. 
Historically, the most common type of microvascular breast reconstruction performed has been abdominally based, including transverse rectus abdominus muscle (TRAM), muscle sparing transverse rectus abdominus muscle (MS-TRAM), superficial inferior epigastric artery (SIEA), and deep inferior epigastric perforator (DIEP) flaps. ${ }^{11-14}$ Conventionally, patients undergoing abdominally based reconstructions have an abundant abdominal tissue that allows for an adequate breast mound to be reconstructed. However, given increasing success with alternate donor site flaps (including profunda artery perforator [PAP], transverse upper gracillis [TUG] flap, superior gluteal artery perforator [SGAP], inferior gluteal artery perforator [IGAP], lateral femoral cutaneous circumflex artery perforator [LFCAP]), as well as success with autologous fat grafting, patients who were historically not considered candidates for microsurgical reconstruction, due to limited donor sites, may now be embraced. ${ }^{15-19}$

Many authors have already demonstrated acceptable results when microsurgical breast reconstruction is performed in overweight, obese, or morbidly obese patients. ${ }^{20-27}$ Similarly, the effect of increased weight on surgical outcomes has also been demonstrated. ${ }^{28}$ Patients with higher body mass index (BMI) are at increased risk of anesthetic complications, cardiovascular events, and respiratory sequelae. ${ }^{29}$ While the relationship between higher BMI patients and surgical outcomes is well established, the relationship between low BMI patients, their eligibility for autologous breast reconstruction, and respective surgical outcomes has yet to be delineated. ${ }^{30-32}$

The implications of examining the influence of low BMI in autologous breast reconstruction extends beyond just identifying a possible difference in complication profile and outcomes. This cohort of women poses some unique challenges. First, unlike higher BMI patients, the donor site availability, especially in nulliparous women, is often limited especially when considering the abdomen as a donor site. Second, matching a preoperatively large breasted woman requiring bilateral reconstruction can pose a challenge using microsurgical breast reconstruction alone. Finally, increasing breast size may be difficult in patients with minimal donor sites.

The authors examine their large volume experience with microsurgical breast reconstruction in lower BMI patients to determine optimal donor site and outcomes.

\section{Patients and Methods}

After obtaining Institutional Review Board approval (R S1203035), all patients undergoing microsurgical breast reconstruction at the New York University Langone Medical Center between November 2007 and November 2011 were reviewed. Patients with BMI greater than or equal to $30 \mathrm{~kg} / \mathrm{m}^{2}$ were included for analysis in this investigation. Patients with BMI less than $30 \mathrm{~kg} / \mathrm{m}^{2}$ or no documented BMI were excluded from the investigation. All reconstructions were performed by six senior surgeons (P.S., B.A., C.A., M.C., J. P.L., and N.S.K.).

The National Institutes of Health categorizes BMI into different groups. Those with BMI less than $18.5 \mathrm{~kg} / \mathrm{m}^{2}$ are classified as "underweight," whereas people with BMI between 18.5 and $24.9 \mathrm{~kg} / \mathrm{m}^{2}$ are "normal weight." If BMI is between 25 and $29.9 \mathrm{~kg} / \mathrm{m}^{2}$, then a patient is classified as "overweight." "Obesity" is defined as BMI greater than or equal to $30 \mathrm{~kg} / \mathrm{m}^{2}$ (http://www.nhlbi.nih.gov/guidelines/obesity/e_txtbk/txgd/411.htm).

From the selected group, patients with BMI less than $30 \mathrm{~kg} / \mathrm{m}^{2}$ were separated into three cohorts. Those patients in Group 1, labeled as "low normal," had BMI between 18.5 and $22 \mathrm{~kg} / \mathrm{m}^{2}$. Women in Group 2, identified as "high normal," had BMI between 22 and $25 \mathrm{~kg} / \mathrm{m}^{2}$. Finally, Group 3 patients, labeled as "overweight," had BMI between 25 and $29.9 \mathrm{~kg} / \mathrm{m}^{2}$.

Reconstructions were compared based on age, incidence of unilateral/bilateral reconstructions, type of mastectomy, timing of reconstruction, indication for surgery (therapeutic/ prophylactic), breast cancer stage, chemotherapy and radiation therapy history, mastectomy specimen weight, flap weight, and flap type. Complications were also analyzed and included both acute complications (arterial thrombosis, venous thrombosis, and hematoma) and long-term complications (fat necrosis, infection, and abdominal wall hernia). Revisionary surgeries were also examined and included breast revision, donor site revision, use of autologous fat grafting as an adjunct, and volume of autologous fat grafting.

Statistical analyses were descriptive (mean, standard error of mean, and range). When appropriate, F-tests, chi-square goodness-of-fit tests, and Freeman-Halton extension of the Fisher exact tests were used (FHE-FET).

\section{Results}

Between November 2007 and November 2011, 199 patients underwent 324 consecutive microsurgical breast reconstructions at New York University Langone Medical Center by six senior surgeons (P.S., B.A., C.A., M.C., J.P.L., and N.S.K.). Of the 199 patients, 42 (66 flaps) were excluded because they had a BMI less than $30 \mathrm{~kg} / \mathrm{m}^{2}$. Therefore, a total of 157 patients undergoing 259 flaps met inclusion criteria. The majority of patients ( $n=102$ [65\%]) underwent bilateral reconstructions, whereas 55 patients (35\%) had unilateral reconstructions.

The study group of women was divided into three groups based on BMI: Group 1 ("low-normal BMI" between 18.5 and $22 \mathrm{~kg} / \mathrm{m}^{2}$ ) included 49 flaps in 30 patients, Group 2 ("highnormal BMI" between 22 and $25 \mathrm{~kg} / \mathrm{m}^{2}$ ) constituted 98 flaps in 58 patients, and finally the largest cohort, Group 3 ("overweight BMI" between 25 and $29.9 \mathrm{~kg} / \mathrm{m}^{2}$ ) had 112 flaps in 69 patients.

\section{Demographics}

The mean age of the patients in Group 1 was $44 \pm 8.73$ years, in Group 2 was $50 \pm 8.66$ years, and in Group 3 it was $51 \pm 8.16$ years. Statistical analysis (F-test) demonstrated that lower BMI patients were more likely to be younger in age $(p<0.001)$. The average BMI was $21 \pm 1.07 \mathrm{~kg} / \mathrm{m}^{2}$ for Group 1, $24 \pm 0.83 \mathrm{~kg} / \mathrm{m}^{2}$ for Group 2, and $27.3 \pm 1.2 \mathrm{~kg} / \mathrm{m}^{2}$ for Group 3. There was a statistically significant difference among the groups when comparing BMI (F-test, $p<0.001$ ).

The majority of flaps in all the three groups were performed for immediate reconstructions (Group $1=82 \%$ 
[ $n=40]$, Group $2=78 \%[n=76]$, and Group $3=69 \%$ $[n=77])$. No statistical difference was noted among the groups when considering timing of reconstruction (chi-square, $p=0.15$ ). Patients undergoing nipple-areolar sparing mastectomy were more likely to be in Groups 1 (38\% [ $n=19])$ and $2(38 \%$ [ $n=37])$ as compared with Group 3 (14.2\% [ $n=16]$ ) (chi-square, $p<0.001$ ) (-Table 1).

\section{Breast Cancer History}

In all the three groups, microsurgical reconstruction was performed for both prophylactic and therapeutic indications. There was no statistically significant difference in the number of reconstructions following prophylactic indications (Group $1=53 \%$ [ $n=26]$, Group $2=48 \%$ [ $n=47]$, and Group $3=44 \%$ [ $n=49]$ ); (chi-square, $p=0.54$ ). When the groups were compared for neoadjuvant or adjuvant radiation, there was no statistically significant difference in the groups (FHE-FET, $p>0.92$ ). Similarly, no differences were found among the groups when looking at delivery of induction or adjuvant chemotherapy (chi-square, $p>0.65$ ) (-Table 2).

\section{Surgical Procedure}

The authors offer the full spectrum of microsurgical breast reconstruction, including the deep inferior epigastric artery perforator (DIEP), the muscle-sparing transverse rectus abdominis muscle (MS-TRAM), SIEA, and stacked DIEP flaps. When abdominal tissue is not available or contraindicated, alternative flaps were performed including the PAP ( $n=12$ flaps, $14.1 \%$ ), transverse upper gracilis (TUG, $n=6$ flaps, $7.0 \%$ ), or SGAP ( $n=1$ flap, $1.2 \%$ ) flaps. However, the majority of flaps performed were abdominally based ( $n=66$ flaps, [77.6\%]). Of these 66 flaps, 57 were DIEP flaps, 5 MS-TRAM flaps, 2 SIEA flaps, and 2 stacked DIEP flaps.

In the 49 flaps performed in the Group 1 cohort, 34 (69.4\%) were abdominally based flaps (DIEP $=25$, MS-TRAM $=8$, stacked DIEP $=1)$. The remaining $15(30 \%)$ were from alternative donor sites (PAP $=11$, TUG $=3$, and SGAP $=1$ ). As such, the ratio of abdominally based flaps to flaps from alternative donor sites (abdominal/alternative flap ratio) in Group 1 was 2.26 (34/15).
Looking at Group 2, 87 (88\%) flaps were from the abdomen $($ DIEP $=69$, MS-TRAM $=15$, stacked DIEP $=2$, and SIEA $=1$ ), whereas $11(12 \%)$ were from alternative sites (PAP $=5$ and TUG $=6$ ). The abdominal/alternative flap ratio for Group 2 was 7.9 (87/11). Finally in Group 3, 108 flaps (96\%) were from the abdomen (DIEP $=68$, MS-TRAM $=39$, SIEA $=1$ ), whereas 4 flaps $(4 \%)$ were from alternative sites (PAP $=4$ ). The abdominal/alternative flap ratio for Group 3 was 27 (108/4).

The abdominal/alternative flap ratio was statistically compared among all three groups (Group $1=2.33$, Group $2=8.09$, and Group $3=27$ ). There was a statistically significant difference among all groups (chi-square, $p<0.001$ ). In all groups, the majority of flaps were abdominally based. However, higher BMI patients were more likely to get abdominally based flaps when compared with the lower BMI patients.

The mean mastectomy specimen weight was $406.9 \pm$ $186.5 \mathrm{~g}$ (range, 190-935 g), while the mean flap weight was $481.7 \pm 193.7 \mathrm{~g}$ (range, 192-1,010 g). The mean mastectomy specimen weight (grams) was statistically different among Group 1 (297 g), Group 2 (466 g), and Group 3 $(628 \mathrm{~g})$ (F-test, $p<0.001)$. The average flap weight (grams) was also statistically different between Group 1 (378 g), Group 2 (367 g), and Group 3 (690 g) (F-test, $p<0.001$ ). Notably, in each cohort, the average flap weight was greater than the average mastectomy specimen weight.

Recipient vessels in all 262 flaps were the internal mammary artery and vein. In the majority of flaps, recipient site exposure was performed through resection of the third rib $(n=200$ flaps, $76.5 \%)$.

\section{Complications}

Examination of adverse events following 262 reconstructions demonstrated that fat necrosis was the most common complication. Eleven flaps in Group 2 (11.2\%) and eleven flaps in Group 3 (9.8\%) had fat necrosis, whereas no reconstructions in Group $1(0 \%)$ had fat necrosis. This was the only statistically significant difference in complication rates among the groups, with a difference in Groups 2 and 3 when compared with Group 1 (FHE-FET, $p<0.05$ ). There was no statistically

Table 1 General patient characteristics

\begin{tabular}{|c|c|c|c|c|c|}
\hline Characteristic & Group 1 & Group 2 & Group 3 & Statistical test & $p$ value \\
\hline Patients & 30 & 58 & 69 & NA & NA \\
\hline Flaps & 49 & 98 & 112 & NA & NA \\
\hline Unilateral, n (\%) & $11(36)$ & $18(31)$ & $26(37)$ & NA & NA \\
\hline Bilateral, $n(\%)$ & $19(64)$ & $40(69)$ & $43(63)$ & NA & NA \\
\hline Age $(y)$, mean $\pm S D$ & $44 \pm 8.73$ & $50 \pm 8.7$ & $51 \pm 8.2$ & F-test & $<0.001$ \\
\hline Body mass index $\left(\mathrm{kg} / \mathrm{m}^{2}\right)$, mean $\pm \mathrm{SD}$ & $20.6 \pm 1.07$ & $24 \pm 0.83$ & $27.3 \pm 1.2$ & F-test & $<0.001$ \\
\hline Immediate, $n(\%)$ & $40(81.6)$ & $76(78)$ & 77 (69) & $x^{2}$ & 0.15 \\
\hline Delayed, $n$ (\%) & $9(18.4)$ & $22(22)$ & $35(31)$ & $x^{2}$ & 0.15 \\
\hline Nipple areolar sparing, $n$ (\%) & $19(39)$ & $37(37.8)$ & $16(14.2)$ & $x^{2}$ & $<0.001$ \\
\hline
\end{tabular}

Abbreviations: NA, not applicable; SD, standard deviation. 
Table 2 Cancer characteristics

\begin{tabular}{|c|c|c|c|c|c|}
\hline & Group 1, $n$ (\%) & Group 2, n (\%) & Group 3, $n$ (\%) & Statistical test & $p$ value \\
\hline Therapeutic indication & $23(47)$ & $51(52)$ & $69(66)$ & $x^{2}$ & 0.54 \\
\hline Prophylactic indication & $26(53)$ & $47(48)$ & $49(44)$ & $x^{2}$ & 0.54 \\
\hline Neoadjuvant radiation & $4(8)$ & $7(7)$ & $9(8.4)$ & FHE-FET & 1 \\
\hline Adjuvant radiation & $5(10)$ & $8(8.2)$ & $10(8.6)$ & FHE-FET & 0.92 \\
\hline Neoadjuvant chemotherapy & $5(10)$ & $8(8.2)$ & $12(10.7)$ & $x^{2}$ & 0.81 \\
\hline Chemotherapy & $6(12)$ & $13(13.3)$ & $19(16.7)$ & $x^{2}$ & 0.65 \\
\hline
\end{tabular}

Abbreviation: FHE-FET, Freeman-Halton extension of the Fisher exact tests.

significant difference in the incidence of seroma when looking at both BMI cohorts and donor sites. - Table 3 summarizes the complications.

\section{Revisionary Surgery}

Recipient and/or donor site revision was offered to all patients. No statistically significant difference was noted in the postoperative breast or donor site revision rates when Groups 1 to 3 were compared (chi-square, $p>0.09$ ). Autologous fat grafting at the reconstructive breast site was performed in Group 1 (28\%), Group 2 (29\%), and Group 3 (18\%) flaps. No statistically significant difference was noted in the rate of fat grafting (chi-square, $p=0.11$ ). Similarly, in patients who received fat grafting, there was no statistically significant difference in transferred volume (Group $1=174 \mathrm{~mL}$, Group $2=173 \mathrm{~mL}$, Group $3=155 \mathrm{~mL}$; F-test $=0.55$ ). For each group, the average volume of fat grafting was compared with the mean flap weight for that group. This ratio of fat grafting volume to mean flap weight was 0.42 for Group 1, 0.51 for Group 2, and 0.32 for Group 3, yielding a statistically significant difference (F-test, $p<0.001$ ), with a greater ratio of fat graft volume to flap volume in nonoverweight patients. Patients did not require mastopexy or breast reduction on the contralateral breast in patients undergoing unilateral reconstruction.

\section{Discussion}

Breast reconstruction remains a common reconstructive procedure performed by plastic surgeons. While there has been a nationwide trend toward increasing numbers of prosthetic reconstructions, microvascular reconstructions have shown higher rates of patient satisfaction in the long term. ${ }^{1-5,8}$ There are several theories to account for this disparity. Outside of major medical centers, microsurgical breast reconstruction can be daunting and only attempted with the ideal surgical candidate. Moreover, patients with low-normal BMI (range, $18.5-22 \mathrm{~kg} / \mathrm{m}^{2}$ ) are often not even considered to be candidates for microsurgical breast reconstruction secondary to apparent lack of adequate donor sites. However, recent advancements in respect to alternative donor site flaps in addition to the use of autologous fat grafting as an adjunct to reconstruction have broadened the indications for autologous microvascular reconstruction. In addition, recent cost-efficiency data revealed microsurgical breast reconstructions to be superior to traditional two-stage tissue expander/implant and direct to implant reconstructions. ${ }^{33}$

This series looks at 262 consecutive microsurgical breast reconstructions in patients with BMI less than $30 \mathrm{~kg} / \mathrm{m}^{2}$ and constitutes the, to our knowledge, largest series in the literature evaluating outcomes and indications for microsurgical reconstructions in patients with low-normal BMI. When comparing patients with low-normal BMI to normal and overweight patients, low-normal BMI patients were more likely to be younger ( 44 vs. 50 vs. 51 years), received alternative donor site flaps (PAP, SGAP, and TUG), and higher ratio of fat graft volume to flap volume (0.42 vs. 0.32 ). This shows that especially very low BMI patients may initially not have adequate amounts flap tissue to entirely reconstruct a breast mount, however, the flaps provide an ideal matrix for future fat grafting with the adjunct of which sufficient volumes may be generated. As such, one may argue that patients who were

Table 3 Complications

\begin{tabular}{|c|c|c|c|c|c|}
\hline & Group $1(n=49)$ & Group $2(n=98)$ & Group $3(n=112)$ & Statistical test & $p$ value \\
\hline Arterial thrombosis, $n$ (\%) & $0(0)$ & $0(0)$ & $1(0.9)$ & FHE-FET & 1 \\
\hline Venous thrombosis, $n$ (\%) & $1(2)$ & $2(2.0)$ & $3(2.7)$ & FHE-FET & 1 \\
\hline Partial flap loss, $n$ (\%) & $1(2)$ & $2(2)$ & $2(1.8)$ & FHE-FET & 1 \\
\hline Hematoma, $n(\%)$ & $0(0)$ & $3(3.1)$ & $2(1.8)$ & FHE-FET & 0.61 \\
\hline Infection, $n(\%)$ & $0(0)$ & $0(0)$ & $0(0)$ & FHE-FET & 1 \\
\hline Hernia, $n(\%)$ & $0(0)$ & $3(3.1)$ & $1(0.9)$ & FHE-FET & 0.411 \\
\hline Fat necrosis, $n(\%)$ & $0(0)$ & $11(11.2)$ & $11(9.8)$ & FHE-FET & 0.028 \\
\hline
\end{tabular}

Abbreviation: FHE-FET, Freeman-Halton extension of the Fisher exact tests. 
formerly not considered potential candidates may now be offered autologous reconstruction. However, in this series (even in low-normal BMI patients) abdominally based flaps, specifically DIEP flaps, remain the most common donor site for reconstruction.

While microsurgical breast reconstruction was first described by Fujino et al in 1976 using the gluteal area as the donor site and further popularized by Shaw in 1983, the abdomen quickly became the workhorse of microsurgical breast reconstruction after published work by Holmström and Hartrampf et al in $1982^{34-37}$ and currently remains the primary donor site for microsurgical breast reconstruction. ${ }^{38,39}$ However, after their initial descriptions, there has been a secondary rise in alternative donor site flaps in the past 10 years starting with the SGAP/IGAP flaps in the 1990s, TUG's in the late 2000s, and PAP flaps in $2010 .^{38}$ These flaps, while not preferred to the abdomen, have been shown in several series to provide a valuable alternative for patients who do not have adequate abdominal donor sites. Baumeister et al report an average BMI of $22.5 \mathrm{~kg} / \mathrm{m}^{2}$ in their series of SGAP reconstructions, but they did not mention the average flap weight. They additionally laud it as a safe and reliable flap. ${ }^{40}$ Granzow et al review of 170 SGAP flaps showed an average flap weight $124 \%$ of the average mastectomy weight, proving that adequate tissue can be gained from this location. ${ }^{41}$ The TUG flap, which was first described by Yousif in 1992, suggests the medial thigh as a donor site, but may cause seroma formation and has been shown to offer only small volumes of tissue. Locke et al also have found an average flap weight of $312 \mathrm{~g}$ (range, 167-480 g), but they did not mention either the mastectomy specimen weight or the BMI of the patient in their investigation. They do however, point out a higher incidence of lipofilling in patients undergoing TUG flaps because of loss of volume over time as well as contour abnormalities. ${ }^{42}$ In our cohort, the average flap weight was $378 \mathrm{~g}$ for the low-normal BMI population, which is similar to the mean found by Locke et al for their cohort of TUG flaps. The average BMI described in patients undergoing PAP flap reconstruction as described by Allen et al was shown to be $23.2 \mathrm{~kg} / \mathrm{m}^{2}$ (range, $18.2-27.5 \mathrm{~kg} / \mathrm{m}^{2}$ ), with a mean flap weight of $385 \mathrm{~g}$ (range, 235-695 g). ${ }^{17}$

In this series, the majority of reconstructions were preformed immediately in all cohorts. There was no statistically significant difference when comparing the numbers of immediate and delayed reconstructions in the three cohorts and also no difference in cancer characteristics when looking at each cohort, with equivalent incidences of reconstructions performed for prophylactic and therapeutic indications. Interestingly, the average mastectomy specimen weight was less than the average flap weight in the low-normal BMI cohort (378 vs. $287 \mathrm{~g}$ ). This finding is somewhat counterintuitive and might lessen the fear to perform autologous breast reconstruction in low BMI patients. When performing autologous reconstruction, the main concern remains creating a breast with adequate volume. In this series with larger flap weights than specimen weights that goal was achieved for this particular group of patients.

This investigation has several limitations. First, it is a retrospective review and inherent bias cannot be avoided. Our institution strongly believes in microsurgical breast reconstruction and therefore offers this type of reconstruction to the majority of patients. In addition, one of the senior authors (R.J.A.) popularized the use of alternative donor site flaps with the use of PAP, SGAP, and IGAP flaps, therefore, our sample may not be representative for other centers around the country. ${ }^{17,18,38}$

Furthermore, there is a low incidence of both acute and long-term complications in all cohorts. Therefore, the study may lack the appropriate power to determine a difference between the cohorts. While many studies have shown increased risk of complications for high-BMI patients undergoing autologous reconstruction, when evaluating our cohort we found overall low complication rates, however, they were evenly distributed among the groups. Contrary to what one might anticipate, complication rates did not go down with decreasing BMI. One should also bear in mind that when trying to harvest maximal amounts of tissue from rather thin patients, contour deformities and increased rates of wound dehiscences as well as poor scarring because of undue tension may result.

In the low-normal BMI cohort, there occurred no cases of fat necrosis. However, fat necrosis is known to be associated with obesity, which is not included in our cohort. Finally, we lack data looking at patient reported satisfaction and esthetic outcomes.

In summary, the choice to undergo microvascular breast reconstruction is multifaceted and the abdomen remains the first line choice for donor site. However, when the abdomen provides an inadequate donor site, surgeons must look to either the thigh or the buttock as an alternative. This flap choice is based on patient preference, surgeon experience, and donor site availability. Furthermore, this study demonstrates the feasibility of performing autologous breast reconstruction also in low BMI patients with overall few complications. While adequate volumes can generally be generated also when using alternative donor sites, the adjunct of fat grafting appears to be especially valuable in low BMI patients.

\section{Conclusion}

Abdominally based free flaps are possible in the majority of patients. In low-normal BMI patients, the harvested flap weight and the mastectomy weight are similar to each other but smaller than both normal BMI and overweight patients. When not desired or unavailable, the use of alternative donor sites remains a viable option. Fat necrosis is more likely in higher BMI patients, and, if utilized, the average volume of fat grafting is similar among various BMI patients. Microsurgical breast reconstruction should be considered a viable option in most patients, regardless of BMI.

Conflict of Interest

No conflict of interest to report.

Financial Disclosure

None. 


\section{References}

1 Alderman AK, Kuhn LE, Lowery JC, Wilkins EG. Does patient satisfaction with breast reconstruction change over time? Twoyear results of the Michigan Breast Reconstruction Outcomes Study. J Am Coll Surg 2007;204(1):7-12

2 Yueh JH, Slavin SA, Adesiyun T, et al. Patient satisfaction in postmastectomy breast reconstruction: a comparative evaluation of DIEP, TRAM, latissimus flap, and implant techniques. Plast Reconstr Surg 2010;125(6):1585-1595

3 Zhong T, McCarthy C, Min S, et al. Patient satisfaction and healthrelated quality of life after autologous tissue breast reconstruction: a prospective analysis of early postoperative outcomes. Cancer 2012;118(6):1701-1709

4 Bodin F, Zink S, Lutz JC, Kadoch V, Wilk A, Bruant-Rodier C. Which breast reconstruction procedure provides the best long-term satisfaction? [in French]. Ann Chir Plast Esthet 2010;55(6):547-552

5 Christensen BO, Overgaard J, Kettner LO, Damsgaard TE. Long-term evaluation of postmastectomy breast reconstruction. Acta Oncol 2011;50(7):1053-1061

6 Gurunluoglu R, Gurunluoglu A, Williams SA, Tebockhorst S. Current trends in breast reconstruction: survey of American Society of Plastic Surgeons 2010. Ann Plast Surg 2013;70(1):103-110

7 Albornoz CR, Bach PB, Pusic AL, et al. The influence of sociodemographic factors and hospital characteristics on the method of breast reconstruction, including microsurgery: a U.S. population-based study. Plast Reconstr Surg 2012;129(5):1071-1079

8 Albornoz CR, Bach PB, Mehrara BJ, et al. A paradigm shift in U.S. Breast reconstruction: increasing implant rates. Plast Reconstr Surg 2013;131(1):15-23

9 Tanna N, Broer PN, Weichman KE, et al. Microsurgical breast reconstruction for nipple-sparing mastectomy. Plast Reconstr Surg 2013;131(2):139e-147e

10 Tanna N, Clayton JL, Roostaeian J, Perry AD, Crisera CA. The volume-outcome relationship for immediate breast reconstruction. Plast Reconstr Surg 2012;129(1):19-24

11 Koshima I, Soeda S. Inferior epigastric artery skin flaps without rectus abdominis muscle. Br J Plast Surg 1989;42(6):645-648

12 Allen RJ, Treece P. Deep inferior epigastric perforator flap for breast reconstruction. Ann Plast Surg 1994;32(1):32-38

13 Blondeel PN, Boeckx WD. Refinements in free flap breast reconstruction: the free bilateral deep inferior epigastric perforator flap anastomosed to the internal mammary artery. Br J Plast Surg 1994; 47(7):495-501

14 Grotting JC. The free abdominoplasty flap for immediate breast reconstruction. Ann Plast Surg 1991;27(4):351-354

15 Arnez ZM, Pogorelec D, Planinsek F, Ahcan U. Breast reconstruction by the free transverse gracilis (TUG) flap. Br J Plast Surg 2004; 57(1):20-26

16 Kind GM, Foster RD. Breast reconstruction using the lateral femoral circumflex artery perforator flap. J Reconstr Microsurg 2011; 27(7):427-432

17 Allen RJ, Haddock NT, Ahn CY, Sadeghi A. Breast reconstruction with the profunda artery perforator flap. Plast Reconstr Surg 2012; 129(1):16e-23e

18 LoTempio MM, Allen RJ. Breast reconstruction with SGAP and IGAP flaps. Plast Reconstr Surg 2010;126(2):393-401

19 Losken A, Pinell XA, Sikoro K, Yezhelyev MV, Anderson E, Carlson GW. Autologous fat grafting in secondary breast reconstruction. Ann Plast Surg 2011;66(5):518-522

20 Chang DW, Wang B, Robb GL, et al. Effect of obesity on flap and donor-site complications in free transverse rectus abdominis myocutaneous flap breast reconstruction. Plast Reconstr Surg 2000;105(5):1640-1648

21 Garvey PB, Buchel EW, Pockaj BA, Gray RJ, Samson TD. The deep inferior epigastric perforator flap for breast reconstruction in overweight and obese patients. Plast Reconstr Surg 2005; 115(2):447-457
22 Jandali S, Nelson JA, Sonnad SS, et al. Breast reconstruction with free tissue transfer from the abdomen in the morbidly obese. Plast Reconstr Surg 2011;127(6):2206-2213

23 Kroll SS, Netscher DT. Complications of TRAM flap breast reconstruction in obese patients. Plast Reconstr Surg 1989;84(6): 886-892

24 Mehrara BJ, Santoro TD, Arcilla E, Watson JP, Shaw WW, Da Lio AL. Complications after microvascular breast reconstruction: experience with 1195 flaps. Plast Reconstr Surg 2006;118(5): 1100-1109, discussion 1110-1111

25 Moran SL, Serletti JM. Outcome comparison between free and pedicled TRAM flap breast reconstruction in the obese patient. Plast Reconstr Surg 2001;108(7):1954-1960, discussion 1961-1962

26 Selber JC, Kurichi JE, Vega SJ, Sonnad SS, Serletti JM. Risk factors and complications in free TRAM flap breast reconstruction. Ann Plast Surg 2006;56(5):492-497

27 Spear SL, Ducic I, Cuoco F, Taylor N. Effect of obesity on flap and donor-site complications in pedicled TRAM flap breast reconstruction. Plast Reconstr Surg 2007;119(3):788-795

28 Flancbaum L, Choban PS. Surgical implications of obesity. Annu Rev Med 1998;49:215-234

29 Whitlock G, Lewington S, Sherliker P, et al; Prospective Studies Collaboration. Body-mass index and cause-specific mortality in 900000 adults: collaborative analyses of 57 prospective studies. Lancet 2009;373(9669):1083-1096

30 Al-Sarraf N, Raza A, Rowley S, et al. Short-term and long-term outcome in low body mass index patients undergoing cardiac surgery. Gen Thorac Cardiovasc Surg 2009;57(2):87-93

31 Okamura Y, Maeda A, Matsunaga K, Kanemoto H, Uesaka K. Negative impact of low body mass index on surgical outcomes after hepatectomy for hepatocellular carcinoma. J Hepatobiliary Pancreat Sci 2012;19(4):449-457

32 Skipworth J, Foster J, Raptis D, Hughes F. The effect of preoperative weight loss and body mass index on postoperative outcome in patients with esophagogastric carcinoma. Dis Esophagus 2009; 22(7):559-563

33 Grover R, Padula WV, Van Vliet M, Ridgway EB. Comparing five alternative methods of breast reconstruction surgery: a costeffectiveness analysis. Plast Reconstr Surg 2013;132(5): $709 \mathrm{e}-723 \mathrm{e}$

34 Shaw WW. Breast reconstruction by superior gluteal microvascular free flaps without silicone implants. Plast Reconstr Surg 1983; 72(4):490-501

35 Fujino T, Harashina T, Enomoto K. Primary breast reconstruction after a standard radical mastectomy by a free flap transfer. Case report. Plast Reconstr Surg 1976;58(3):371-374

36 Holmström $\mathrm{H}$. The free abdominoplasty flap and its use in breast reconstruction. An experimental study and clinical case report. Scand J Plast Reconstr Surg 1979;13(3):423-427

37 Hartrampf CR, Scheflan M, Black PW. Breast reconstruction with a transverse abdominal island flap. Plast Reconstr Surg 1982;69(2): 216-225

38 Healy C, Allen RJ Sr. The evolution of perforator flap breast reconstruction: twenty years after the first DIEP flap. J Reconstr Microsurg 2014;30(2):121-125

39 Granzow JW, Levine JL, Chiu ES, Allen RJ. Breast reconstruction using perforator flaps. J Surg Oncol 2006;94(6):441-454

40 Baumeister S, Werdin F, Peek A. The sGAP flap: rare exception or second choice in autologous breast reconstruction? J Reconstr Microsurg 2010;26(4):251-258

41 Granzow JW, Levine JL, Chiu ES, Allen RJ. Breast reconstruction with gluteal artery perforator flaps. J Plast Reconstr Aesthet Surg 2006;59(6):614-621

42 Locke MB, Zhong T, Mureau MA, Hofer SO. Tug 'O' war: challenges of transverse upper gracilis (TUG) myocutaneous free flap breast reconstruction. J Plast Reconstr Aesthet Surg 2012;65(8): $1041-1050$ 